\title{
Effect of protein corona magnetite nanoparticles derived from bread in vitro digestion on Caco-2 cells morphology and uptake
}

\author{
Desirè Di Silvio ${ }^{\mathrm{a}, \mathrm{b}, * *}$, Neil Rigby $^{\mathrm{b}}$, Balazs Bajka $^{\mathrm{b}}$, Alan Mackie ${ }^{\mathrm{b}}$, \\ Francesca Baldelli Bombelli $\mathrm{c}, *$ \\ a School of Pharmacy, University of East Anglia, Norwich Research Park, Norwich, United Kingdom \\ b Institute of Food Research, Norwich Research Park, Norwich, United Kingdom \\ c Department of Chemistry, Materials and Chemical Engineering Giulio Natta, Politecnico di Milano, Milan, Italy
}

\begin{abstract}
Nanoparticles (NPs) in biological fluids immediately interact with proteins forming a biomolecular corona (PC) that imparts their biological identity. While several studies on the formation of the PC in human plasma have been reported, the PC of orally administrated NPs has been less investigated, mostly in the presence of a food matrix. In fact, food matrixes when digested are subject of several dynamic changes that will certainly affect the PC formed on the NPs. The lack of studies on this topic is clearly related to the difficulty in isolating representative PC NPs from such a complex environment. In this work magnetite NPs were added to in vitro simulated digestion simultaneously with bread and PC NPs were isolated after gastric and duodenal phases by sucrose gradient ultracentrifugation (UC). The PC NPs were characterized in terms of size and protein composition. Translocation studies were then performed on Caco-2 mono-layers in a serum free environment and cell morphology was characterized by confocal microscopy. PC NPs isolated from gastric and duodenal phases were different in size, surface charge and protein corona composition. NP cellular uptake was enhanced by the digestive PC inducing morphology changes in the cell monolayer. Overall, in this work we were able to isolate PC NPs from digested fluids in the presence of a food matrix and study their biological response on Caco-2 cells.
\end{abstract}

\author{
Abbreviations: \\ NP, nanoparticle \\ UC, ultracentrifugation \\ PC, protein corona \\ GI, gastrointestinal \\ SSF, simulated salivary fluid \\ SGF, simulated gastric fluid \\ SIF, simulated intestinal fluid \\ PMAO, poly (maleic)-alt-1-octadecene \\ $\mathrm{CF}$, carboxyfluo-rescien \\ FA, fluoresceinamine \\ SFM, serum free medium
}

\footnotetext{
* Corresponding author.

** Corresponding author at: School of Pharmacy, University of East Anglia, Norwich Research Park, Norwich, United Kingdom.

E-mail address: francesca.baldelli@polimi.it (F. Baldelli Bombelli).
}

\section{Introduction}

When NPs are in a biological environment they readily interact with the surrounding proteins that adsorb to the surface forming a PC (Walczyk et al., 2010). The PC composition confers a biological identity to the NP (Cedervall et al., 2007; Lynch et al., 2007; Walczyk et al., 2010) that determines NP-cell interactions (Lundqvist et al., 2008; Lynch et al., 2007; Monopoli et al., 2012; Soenen et al., 2015; Walkey et al., 2014).

PCs from blood have been extensively studied for many NPs (Cai et al., 2013; Foroozandeh and Aziz, 2015; Ghavami et al., 2013; Jansch et al., 2012; Sherwood et al., 2014; Treuel et al., 2015) and

only recently PCs obtained from in vitro models have been compared to those isolated from blood in vivo (Hadjidemetriou et al., 2015) and the dynamic nature of the blood circulation seemed to modify corona composition and morphology. In contrast, PCs formed in fluids other than blood, such as gastrointestinal (GI) fluids have been less extensively investigated, even though they are important for pharmacological and toxicological reasons (Clift et al., 2010; Lefebvre et al., 2014; Setyawati et al., 2015). In fact, the oral delivery route is one of the most commonly used for drug delivery and ingestion of NPs represents a probable way for NPs to enter the human body, being extensively used in food industry as additives (flavour, texture, stability improvements) (Borel and Sabliov, 2014) and in packaging (Clift et al., 2010; Maiorano et al., 2010; Peng et al., 2013).

The GI tract is a complex environment characterized by $\mathrm{pH}$ ranging from two to eight, high electrolyte concentrations, enzymes and food matrix that change dynamically. All these elements can affect NPs colloidal stability (Böhmert et al., 2013; Yang et al., 2014; Zimmermann and Müller, 2001) and PC composition with con-sequences for bioavailability and toxicity. For example, recently, core-shell gold NPs were shown to be subject to proteolytic 
Table 1

Final concentrations of the salts used in SSF, SGF, SIF according to INFOGEST recommendations (Minekus et al., 2014).

\begin{tabular}{|c|c|c|c|}
\hline & $\mathrm{SSF}[\mathrm{mmol} / \mathrm{l}]$ & $\mathrm{SGF}[\mathrm{mmol} / \mathrm{l}]$ & $\mathrm{SIF}[\mathrm{mmol} / \mathrm{l}]$ \\
\hline $\mathrm{KCl}$ & 15.1 & 6.9 & 6.8 \\
\hline $\mathrm{KH}_{2} \mathrm{PO}_{4}$ & 3.7 & 0.9 & 0.8 \\
\hline $\mathrm{NaHCO}_{3}$ & 13.6 & 25 & 85 \\
\hline $\mathrm{NaCl}$ & - & 47.2 & 38.4 \\
\hline $\mathrm{MgCl}_{2}\left(\mathrm{H}_{2} \mathrm{O}\right)_{6}$ & 0.15 & 0.1 & 0.33 \\
\hline$\left(\mathrm{NH}_{4}\right)_{2} \mathrm{CO}_{3}$ & 0.06 & 0.5 & - \\
\hline $\mathrm{CaCl}_{2}\left(\mathrm{H}_{2} \mathrm{O}\right)_{2}{ }^{\mathrm{a}}$ & 1.5 & 0.15 & 0.6 \\
\hline $\mathrm{KCl}$ & 15.1 & 6.9 & 6.8 \\
\hline
\end{tabular}

a It was added to the final mixture to avoid precipitation.
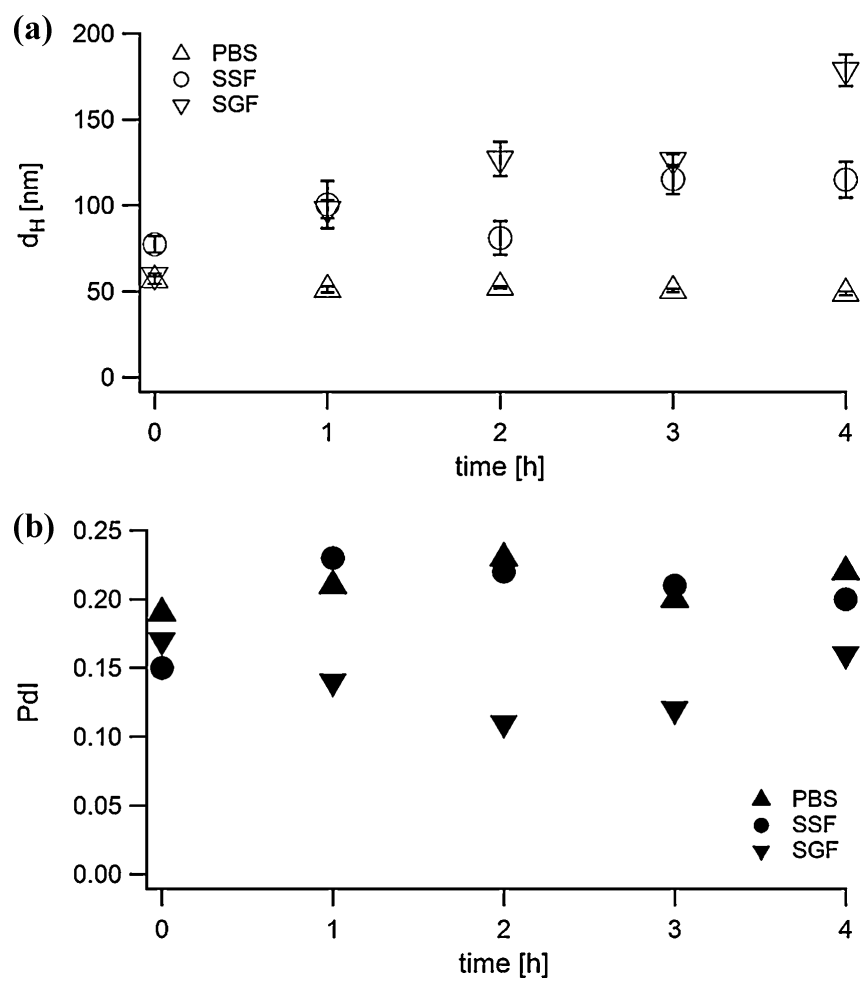

Fig. 1. $\mathrm{Fe}_{3} \mathrm{O}_{4} \mathrm{NPs}$ colloidal stability. (a) Hydrodynamic diameters variation by time for $\mathrm{Fe}_{3} \mathrm{O}_{4}$ NPs incubated in PBS (triangle), in SSF (circle) and in SGF (upside-down triangle) at $37^{\circ} \mathrm{C}$. (b) PdI variation for the same samples. Hydrodynamic diameters and PdI were obtained by DLS from cumulant analysis of the auto-correlation data.

Table 2

Characterization of $\mathrm{Fe}_{3} \mathrm{O}_{4}$ NPs in PBS by DLS and NTA and cognate PC complexes isolated from simulated gastric fluid by UC (G-NPs).

\begin{tabular}{lcc}
\hline & $\mathrm{Fe}_{3} \mathrm{O}_{4}-\mathrm{NPs}$ & \multicolumn{1}{c}{$\mathrm{G}-\mathrm{NPs}$} \\
\hline$d_{\mathrm{H}}[\mathrm{nm}]^{\mathrm{a}}$ & $73 \pm 8$ & $245 \pm 13$ \\
$\mathrm{SD}[\mathrm{nm}]^{\mathrm{b}}$ & $32 \pm 18$ & $60 \pm 17$ \\
$d_{\mathrm{H}}[\mathrm{nm}]^{\mathrm{c}}$ & $46.9 \pm 0.9$ & $199.2 \pm 0.2$ \\
$\mathrm{PdI}$ & $0.20 \pm 0.01$ & $0.26 \pm 0.01$ \\
$\mathrm{Zp}[\mathrm{mV}]$ & $-21.6 \pm 1.5$ & $-4.3 \pm 0.2$
\end{tabular}

All data were presented as the average of three indipendent measurements with relative standard deviation.

a Hydrodynamic diameter $\left(d_{\mathrm{H}}\right)$ was calculated avaraging the hydrodynamic diameters of all NPs tracked in a particle-by-particle modality by NTA.

b $\mathrm{SD}$ is the standard deviation on all the hydrodynamyc diameters measured in a particle-by-particle modality by NTA.

c Hydrodynamic diameter $\left(d_{\mathrm{H}}\right)$ obtained by DLS from the cumulant analysis of the auto-correlation data.

d Polydispertity indexes (PdI) were obtained by DLS from the cumulant analisys of the auto-correlation data. (a)

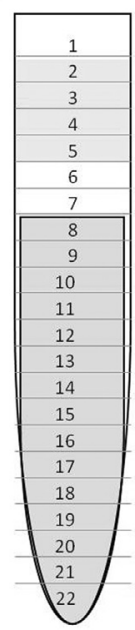

(b) $\mathrm{MW}$

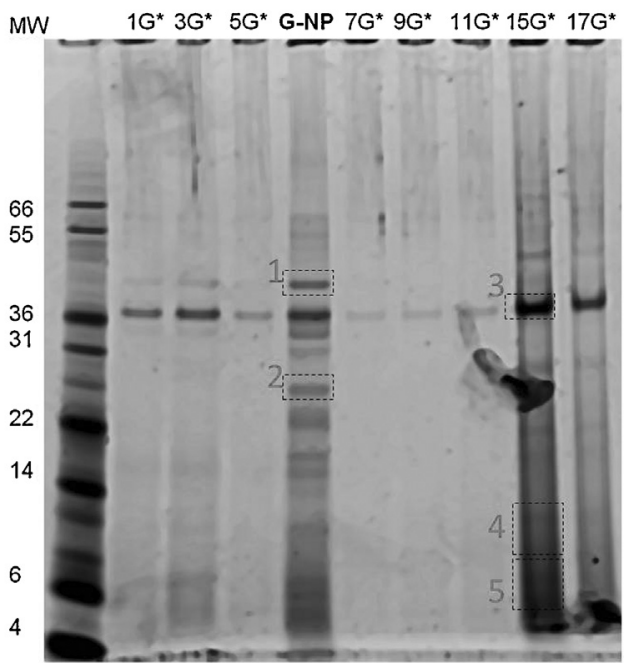

Fig. 2. Isolation of PC-NPs complexes from simulated gastric fluid. (a) Schematic drawing of the sucrose layers of the UC of the simulated gastric fluid enriched with bread and NPs. Upper fractions (2-5) contained NPs, while lower fractions contained floating starch residues. A control experiment only on digested bread without NPs was also performed in the same conditions. (b) SDS-PAGE of fractions 2-5 (G-NP lane) and fractions isolated from the digestion without NPs (lanes marked with * symbol). Bands labelled with dashed lines and numbers were characterized by LC-MS.

(a)
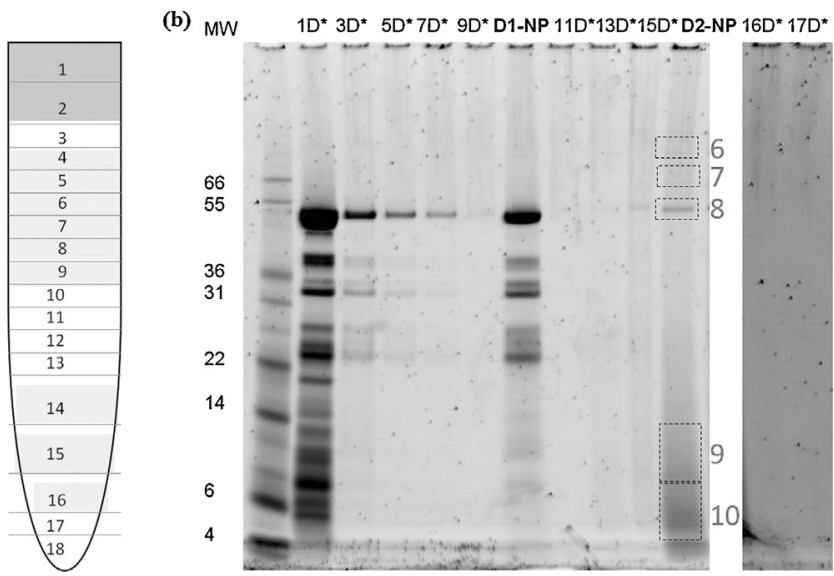

Fig. 3. Isolation of PC-NPs complexes from simulated intestinal fluid. (a) Schematic drawing of the sucrose layers of the UC of the simulated duodenal fluid enriched with bread and NPs. Highlighted fractions at the top of the gradient contained bile salts and low density peptides. Pink fractions (4-9 and 14-16) contained NPs. A control experiment only on digested bread without NPs was also performed in the same conditions. (b) SDS-PAGE of fractions 4-9 and 14-16 (D1-NP and D2-NPs lanes respectively). Lanes labelled with * were loaded with fractions from the control without NPs. Bands labelled with dashed lines and numbers were characterized by LC-MS

enzymes and $\mathrm{pH}$ conditions in lysosomes when they were internalized by macrophages and endothelial cells. The shell was partially removed and PC affected by the altered coating (Kreyling et al., 2014). Moreover, Docter et al. (2015) in a recent review highlighted the lack of reports about the influence of PC complexes on the GI tract albeit some studies revealed that upon NPs exposure gut homeostasis was altered.

Several models have been proposed to simulate the ingestion process. In vivo mammalian models have been used, but in vitro models are generally preferred because they are more versatile, less expensive and do not require ethical approval. In vitro models can be dynamic when physical processing of the food and temporal changes of the gastrointestinal conditions ( $\mathrm{pH}$ changes, enzymes and electrolytes concentrations) mimic 
Table 3

Characterization by DLS and NTA of $\mathrm{Fe}_{3} \mathrm{O}_{4}$ NPs in PBS and PC complexes isolated from intestinal fluids by UC after dialysis (D1- and D2-NPs).

\begin{tabular}{lccc}
\hline & $\mathrm{Fe}_{3} \mathrm{O}_{4}-\mathrm{NPs}$ & $\mathrm{D} 1-\mathrm{NPs}$ & \multicolumn{1}{c}{ D2-NPs } \\
\hline$d_{\mathrm{H}}[\mathrm{nm}]^{\mathrm{a}}$ & $73 \pm 8$ & $116 \pm 14$ & $143 \pm 17$ \\
$\mathrm{SD}[\mathrm{nm}]^{\mathrm{b}}$ & $32 \pm 18$ & $55 \pm 9$ & $48 \pm 9$ \\
$d_{\mathrm{H}}[\mathrm{nm}]^{\mathrm{c}}$ & $46.9 \pm 0.9$ & $85.7 \pm 2.9$ & $116.6 \pm 5.2$ \\
$\mathrm{PdI}[\mathrm{nm}]^{\mathrm{d}}$ & $0.20 \pm 0.01$ & $0.21 \pm 0.02$ & $0.23 \pm 0.01$ \\
$\mathrm{Zp}[\mathrm{mV}]$ & $-21.6 \pm 1.5$ & $-24.2 \pm 0.4$ & $-16.1 \pm 1.2$ \\
\hline
\end{tabular}

All data were presented as the average of three indipendent measurements with relative standard deviation.

${ }^{a}$ Hydrodynamic diameter $\left(d_{\mathrm{H}}\right)$ was calculated averaging the hydrodynamic diameters of all NPs tracked in a particle-by-particle modality by NTA.

b SD is the standard deviation on all the hydrodynamyc diameters measured in a particle-by-particle modality by NTA.

c Hydrodynamic diameter $\left(d_{\mathrm{H}}\right)$ obtained by DLS from the cumulant analysis of the auto-correlation data.

d Polydispertity indexes (PdI) were obtained by DLS from the cumulant analisys of the auto-correlation data.

the in vivo digestive process. They can also be static when there are synthetic fluids that reproduce chemically and enzymatically the environmental conditions encountered in the distinct areas of the GI tract and the meal/enzyme ratio is kept constant. The INFOGEST COST action network aimed to give some recommen-dations to achieve standard conditions for static in vitro digestion to allow comparison of results among research groups (Minekus et al., 2014). In this work we adopted a static in vitro model following INFOGEST recommendations as described in detail in Section 2.2.

The lack of absorption in most in vitro models can be partially covered by cell culture models. Cell monolayers are often used to assess epithelial permeability of compounds. Immortalized Caco- 2 cell lines are commonly used because they are able to form an adherent monolayer that shows some characteristics of the gut epithelium. Thus, translocation studies can be performed when they are grown on semi-permeable membranes mimicking the transport of substances from the apical to the basolateral side (Lefebvre et al., 2014). Other models are based on Caco-2 co-culture with other cells that are able to express mucus (Ensign et al., 2012).

There are many studies on translocation of NPs across Caco-2 monolayers (Lefebvre et al., 2014), but most of them deal with in situ NPs. Walczak et al. (2015b) investigated polymeric NPs transloca-tion in different in vitro models taking into account the formation of a corona upon exposure to complete cell medium. Afterwards, the same group showed that NPs, if subject of in vitro digestion, express a different corona upon contact with cell culture medium compared to pristine NPs (Walczak et al., 2015a). On the other hand, Lichtenstein et al. (2015) studied the impact of food on silver NPs digestion. They modified the in vitro digestion model of Böhmert et al. (2013) by adding food components to the digestive fluid. They found that the corona originating from food digestion was able to stabilize NPs in full cell medium, while NPs digested with-out food extensively aggregated. They showed also that the NPs digested with food had similar uptake to nondigested NPs, while those digested without food showed less uptake.

To the best of our knowledge there is no previous work in which NPs subjected to simulated digestion in the presence of food matrix were isolated from the digestive chime and characterized in terms of corona composition and structure. In our previous work we showed the suitability of sucrose gradient ultracentrifugation (UC) to recover PC complexes representative of those in situ incubating magnetite NPs with gastric and duodenal digestion of skimmed milk powder (Di Silvio et al., 2015). The NPs were coated with a polymer shell functionalized with a fluorescent molecule, which was shown to be stable during the digestion. Here we describe the simultaneous simulated in vitro digestion of NPs and bread as a more representative model of the in vivo digestive process. PC complexes were isolated by sucrose gradient UC after gastric and duodenal phases. The recovered PC complexes were characterized by size, surface charge and corona composition by dynamic light scattering (DLS), nanoparticles tracking analysis (NTA), SDS-PAGE and LC-MS. The effect of the corona on uptake and translocation through a Caco-2 monolayer was investigated in serum free environment to stress on the role of the corona formed during digestion. Laser scanning confocal microscopy (LSCM) was used to assess morphological alteration in the monolayer.

\section{Materials and methods}

\subsection{Fluorescent magnetite NPs synthesis}

Carboxylated $\mathrm{Fe}_{3} \mathrm{O}_{4}$ NPs were synthesized following the protocol of Sun et al. (2003) and coated by poly (maleic)-alt-1octadecene (PMAO, Sigma) according to Lin et al. (2008) for water trans-fer. Sucrose density gradient ultracentrifugation (6.6-66 w/ $\mathrm{w} \%, 187 \mathrm{k} \mathrm{rcf}, 4 \mathrm{~h}, 20^{\circ} \mathrm{C}$ ) was performed to purify them from excess polymer. Purified NPs were fluorescently labelled by BODIPY ${ }^{\circledR}$ FLEDA (LifeTechnologies) through N-(3-dimethylaminopropyl)-N'ethylcarbodiimide hydrochloride chemistry (Sigma). This dye was chosen because, according to the supplier, its quantum yield is min-imally affected by the $\mathrm{pH}$ and polarity of the solvent (Karolin et al., 1994). Unbound free dye was removed by Amicon centrifugal filters (50 kDa MWCO, 360 rcf). Sucrose, sodium phosphate dibasic, potassium phosphate monobasic, sodium chloride and potassium chloride are from SIGMA.

\subsection{In vitro static digestion}

The in vitro model adopted in this work to simulate digestion is based on INFOGEST recommendations (Minekus et al., 2014). The protocol aims to mimic the in vivo conditions that describe the oral, gastric and small intestinal phases. Specific $\mathrm{pH}$, electrolyte concentrations and enzymes characterize each phase. In Table 1, a summary of the electrolytes final concentrations in the simulated salivary fluid (SSF), simulated gastric fluid (SGF) and simulated intestinal fluid (SIF) is reported. The $\mathrm{pH}$ was adjusted by concentrated solutions of $\mathrm{HCl}$ and $\mathrm{NaOH}$ during the digestion at $\mathrm{pH} 3$ and 7 for SGF and SIF, respectively. Calcium salt solutions were added to the final mixture of each phase to avoid precipitation in the electrolyte solutions.

The digestive simulation was performed at $37{ }^{\circ} \mathrm{C}$ under magnetic stirring. The oral phase lasted for $2 \mathrm{~min}$ and $\alpha$-amylase was not added to the mixture (Woolnough et al., 2010). The gastric phase lasted for 2 h: SGF and Porcine Pepsin (final activity $2000 \mathrm{U} /$ $\mathrm{ml}$, Sigma Pepsin, P7012) were added. In the duodenal phase SIF, bile salts $(160 \mathrm{mM})$ and pancreatin from porcine pancreas (final trypsin activity $100 \mathrm{U} / \mathrm{ml}$, Sigma, P7545) were added to the mixture. Pan-creatin in SIF formed a fibrous precipitate that was centrifuged at $4{ }^{\circ} \mathrm{C}$ for $1 \mathrm{~min}$. Negligible loss of activity was assessed using the p-toluene-sulfonyl-L-arginine methyl ester (TAME) assay for trypsin activity (Hummel, 1959).

\subsection{Sucrose gradient ultracentrifugation}

Solutions of sucrose (Sigma) were prepared at increasing concentration from $6.6 \mathrm{w} / \mathrm{w} \%$ to $66 \mathrm{w} / \mathrm{w} \%$ in water and $11 \mathrm{ml}$ of linear sucrose gradient were layered in $13 \mathrm{ml}$ tubes and left to equilibrate overnight before being subjected to ultracentrifugation (UC) using a SW41 Ti rotor (Beckman Coulter) at $20^{\circ} \mathrm{C}$. $0.5 \mathrm{ml}$ of sample was loaded in two tubes. UC was run for $1 \mathrm{~h}$ at $20^{\circ} \mathrm{C}$ at $48 \mathrm{k}$ rcf and $195 \mathrm{k}$ rcf for gastric and duodenal samples, respectively. Collected fractions were analyzed and those fractions containing PC NPs were 
Table 4

Selected peptides common to G-NPs and D2-NPs complexes. Bands were highlighted in Figs. 2b and 3b.

\begin{tabular}{|c|c|c|c|c|c|}
\hline Name & Taxonomy & Nominal mass & Band & Coverage $^{\mathrm{a}}$ & Score $^{b}$ \\
\hline \multirow[t]{4}{*}{ Vicilin $47 \mathrm{k}$} & Pisum sativum & 49542 & B1 & 37 & 188 \\
\hline & & & B2 & 34 & 172 \\
\hline & & & B5 & 47 & 264 \\
\hline & & & B6 & 18 & 109 \\
\hline \multirow[t]{3}{*}{ Legumin } & Pisum sativum & 59633 & B9 & 26 & 268 \\
\hline & & & $\mathrm{B} 1^{*}$ & 23 & 115 \\
\hline & & & B2 & 26 & 265 \\
\hline \multirow[t]{2}{*}{0.19 dimeric alpha-amylase inhibitor } & Aegilops tauschii & 13881 & B4 & 77 & 792 \\
\hline & & & B5 & 70 & 343 \\
\hline \multirow[t]{2}{*}{ Dimeric alpha-amylase inhibitor } & Triticum dicoccoides & 15666 & B9 & 29 & 213 \\
\hline & & & B10 & 49 & 215 \\
\hline \multirow[t]{2}{*}{ Lectin } & Cicer arietinum & 26363 & B2 & 48 & 265 \\
\hline & & & B6 & 37 & 102 \\
\hline \multirow[t]{6}{*}{ Adh1p } & S. cerevisiae & 37296 & B3 & 51 & 322 \\
\hline & & & B6 & 19 & 94 \\
\hline & & & B7 & 20 & 98 \\
\hline & & & B8 & 38 & 156 \\
\hline & & & B9 & 54 & 361 \\
\hline & & & B10 & 56 & 676 \\
\hline
\end{tabular}

a Sequence coverage is calculated by dividing the number of amino acids observed by the protein amino acid length.

b The score is a probability based score. The total score is the probability $(P)$ that the observed match is a random event. Score $=-10 \times \log 10(P)$.

dialysed against PBS (3-5k MWCO, SpectrumLabs) overnight at $4{ }^{\circ} \mathrm{C}$. Before analysis, the sample volume was reduced to $300 \mu \mathrm{l}$ by $50 \mathrm{kDa}$ MWCO Amicon centrifugal concentrator at $405 \mathrm{rcf}$.

\subsection{Dynamic Light Scattering and Z-potential}

Hydrodynamic diameters of dialysed dispersions were measured by Zetasizer SZ (Malvern). $50 \mu$ l of the samples were diluted in $400 \mu \mathrm{l}$ of PBS in $1 \mathrm{ml}$ cuvette to obtain attenuation values in the 7-9 range and measured at $25^{\circ} \mathrm{C}$ equilibrating samples for $120 \mathrm{~s}$ prior to measurement. Data were presented as an average of three measurements. The Z-averaged sizes (Z-ave) and the polydispersity index (PdI) were obtained by cumulant analysis of the auto-correlation functions. Zeta potential (Zp) was measured using disposable capillary cells (Malvern). Data are the average of three measurements of 10 runs each.

\subsection{Nanoparticles tracking analysis}

Samples in sucrose were analyzed by NTA diluting them with MQ water to reach an ideal concentration of $1-3 \times 10^{8} \mathrm{NPs} / \mathrm{ml}$. Three videos of $60 \mathrm{~s}$ were collected for each sample and analyzed by NTA software. The software is able to track NPs individually and calculate their diffusion coefficients. In this way, a mean value of the hydrodynamic diameter (Mean) is obtained with the relative standard deviation (SD) with respect to all tracks. Results are presented as an average of three independent measurements.

\subsection{SDS-PAGE}

$30 \mu \mathrm{l}$ of sample were added to $15 \mu \mathrm{l}$ of SDS-PAGE loading buffer $3 x\left(10 \%\right.$ DTT, Thermo Scientific) and kept at $98^{\circ} \mathrm{C}$ for $5 \mathrm{~min}$. Digested samples that did not contain NPs were mixed to the loading buffer without any previous treatment and denatured as above. $20 \mu \mathrm{l}$ of samples and $5 \mu \mathrm{l}$ of molecular ladder (Mark12 Unstained standard, Invitrogen) were loaded on $10 \%$ Precast Gel NuPAGE (Life Technology). The running buffer used was MES buffer (NuPAGE 20×, Invitrogen). Gels were run at $200 \mathrm{~V}$ for $35 \mathrm{~min}$. Gels were developed by Sypro Ruby Protein Stain (Biorad) and imaged by Biorad Pharos FX+, the software used to elaborate images was Image Lab (Biorad).

\section{7. $L C-M S$}

ProPick instrument was used to locate and cut bands from the gel. Bands were digested at $37^{\circ} \mathrm{C}$ for $3 \mathrm{~h}$ by $10 \mathrm{mM}$ ammonium bicarbonate $10 \mathrm{ng} / \mu$ l trypsin gold (Promega, V528A in $50 \mathrm{mM}$ Acetic Acid) (prepared 01-May-14). 1\% formic acid (Sigma) was added prior freezing samples and storing at $-80^{\circ} \mathrm{C}$. Samples were washed in $50 \%$ acetonitrile (Fisher), vortexed and dried out at the Low Drying setting (no heat) on a Speed Vac SC110 (Savant) fitted with a refrigerated condensation trap and a Vac V-500 (Buchi). Samples were again stored at $-80^{\circ} \mathrm{C}$ until ready for Orbitrap analysis. Protein identification was achieved by combining spectrum quality scoring obtained from a conventional database search program MASCOT (Matrix Science, London, England). Search parameters were peptide mass and fragment mass tolerances of $5 \mathrm{ppm}$ and 0.5 Da respectively, variable modification was oxidation (M), fixed modification carbamidomethyl (C), enzyme specificity was trypsin, two missed cleavages were allowed. All taxonomy database was searched. Peptides with high scores were listed. The score represents the probability that the match found is a random event, so the higher it is the more likely is the match.

\subsection{Translocation experiment and laser scanning confocal microscopy (LSCM)}

Caco-2 monolayer was used as model to study the effect of the digested corona on NPs cellular uptake and transport across the membrane in the gastro-intestinal tract. Cells at the 12th passage were seeded at a concentration of $2.5 \times 10^{5}$ cells $/ \mathrm{ml}$ on an HTS transwell 24 well plate, $0.4 \mu \mathrm{m}$ pore size (Costar, 3524, Corning). Cells were incubated in $37^{\circ} \mathrm{C}, 5 \% \mathrm{CO}_{2} / 95 \%$ air. Cells were cultured in RPMI-1640 supplemented with $10 \%$ heat-inactivated foetal bovine serum (FBS), $2 \mathrm{mM}$ L-glutamine, $100 \mu \mathrm{g} / \mathrm{ml}$ penicillin and $100 \mu \mathrm{g} / \mathrm{ml}$ streptomycin all purchased Life Technologies, Carlsbad, CA. Media was changed every two days and Transepithelial Electric Resistance (TEER) was measured by MilliCell (Millipore) just before changing the media to assess the integrity of the cell barrier. TEER was expressed in $\Omega \mathrm{cm}^{-1}$ as the product $\left(R-R_{\mathrm{b}}\right) \times A$, where $R$ and $R_{\mathrm{b}}$ are the resistance $(\Omega)$ of the cells and the blank, respectively, and $A$ is the surface area of the insert $(\mathrm{cm})$. When the TEER values were $>300 \Omega \mathrm{cm}^{-1}$, transport experiment was performed. The 

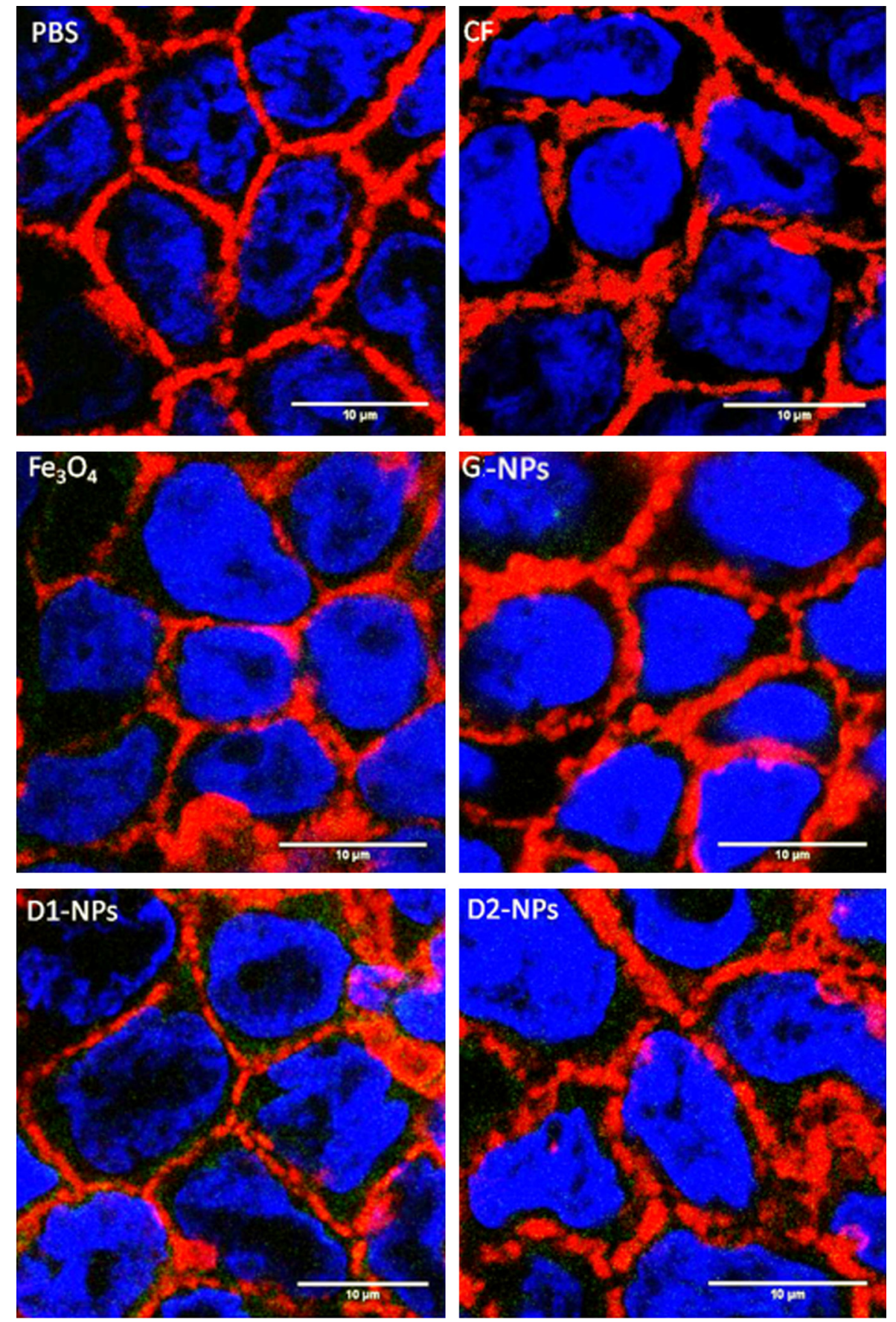

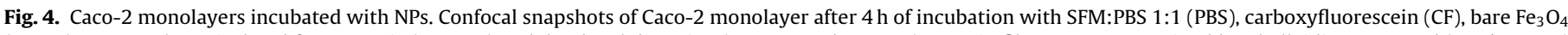

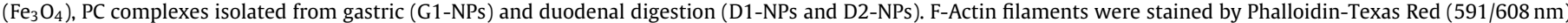
and nuclei by Hoechst $33342(350 / 461 \mathrm{~nm})$. $\mathrm{Fe}_{3} \mathrm{O}_{4}$ NPs were labelled by BODIPY FL-EDA (500/510 nm). Images were rendered using ImageJ.

apical and basolateral chambers were filled with serum free medium (SFM) after PBS $(3 \times)$ rinsing to remove phenol red and FBS proteins from the chambers and cells were allowed equilibrating for $1 \mathrm{~h} .100 \mu \mathrm{l}$ of the apical medium were replaced with PC NPs from the gastric digestion (G-NPs) and the duodenal digestion (D-NPs) to get a final concentration of $2 \times 10^{12} \mathrm{NPs} / \mathrm{ml}$. Control wells with pristine $\mathrm{Fe}_{3} \mathrm{O}_{4}$ NPs at the same concentration as the PC complexes, PBS $(100 \mu \mathrm{l})$ and carboxyfluorescein (CF, Sigma) were prepared in parallel and incubation at $37^{\circ} \mathrm{C}$ was performed for $4 \mathrm{~h}$. $100 \mu \mathrm{l}$ of basolateral medium were sampled at 60,120,180 and $240 \mathrm{~min}$ and replaced with the same volume of fresh medium. TEER after $4 \mathrm{~h}$ was measured to assess the effect of the NPs on the transepithelial electric resistance. The presence of NPs in the collected medium from the basolateral chamber was revealed by fluorescence using a plate reader exciting at $492 \mathrm{~nm}$ and collecting emission at $520 \mathrm{~nm}$. Cells were three times washed with PBS and fixed with $5 \%$ formaldehyde for $10 \mathrm{~min}$, then they were treated with Triton-X $0.5 \%$ for $3 \mathrm{~min}$ and again washed for three times with PBS. F-Actin staining was performed by Texas-Red Phalloidin (6.6 $\mu \mathrm{M}$, Invitrogen) and nuclei by Hoechst 33258 ( $2 \mu \mathrm{g} / \mathrm{ml}$, Sigma). After staining, the membranes were cut from the insert, placed on a glass slide and covered by a coverslip with mounting medium in between (Vectashield, Vector). Zeiss LSM510-META confocal microscope (UEA) was used to image cell monolayer and NPs using a multi-channel 


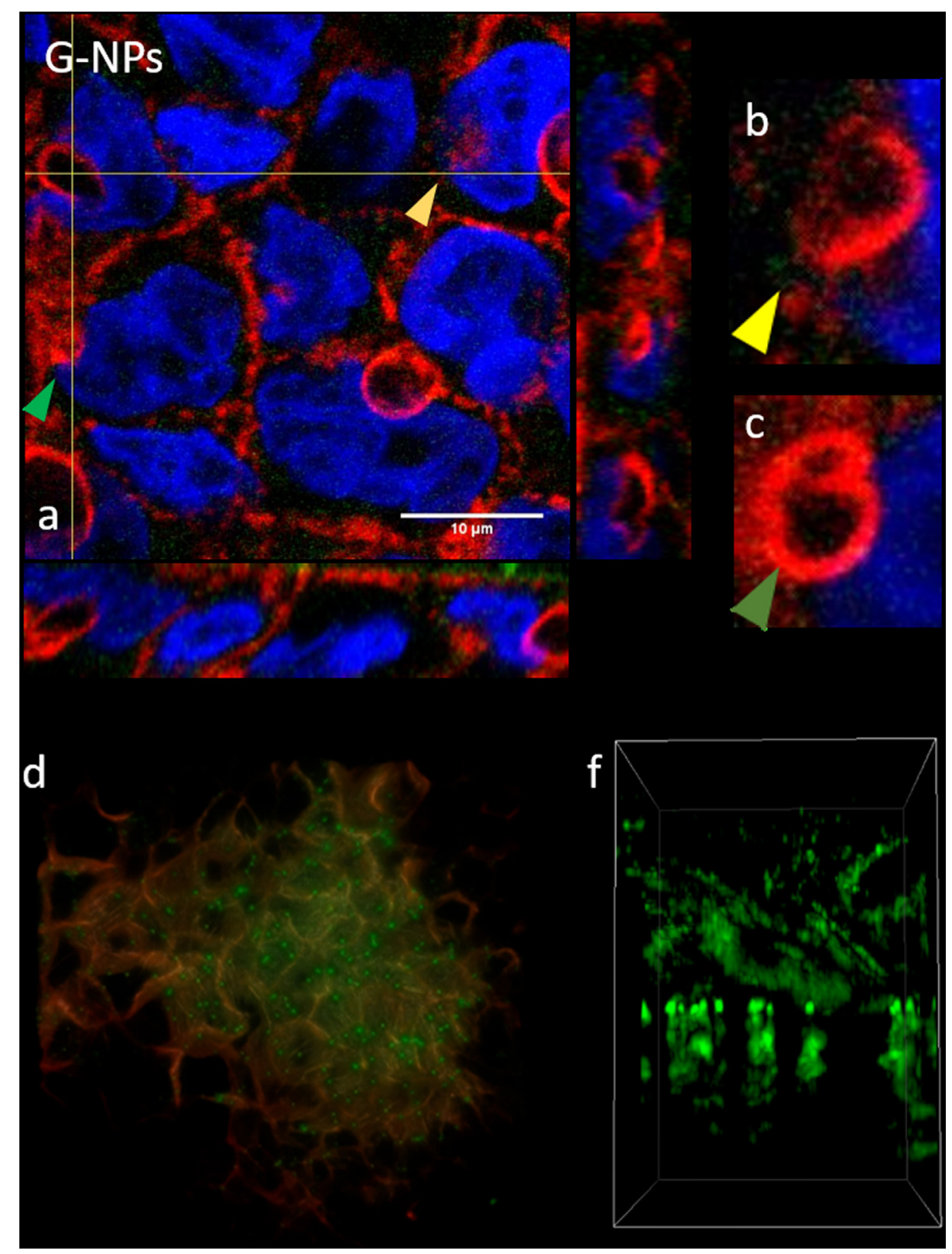

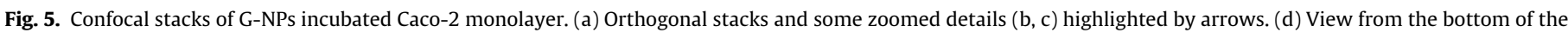

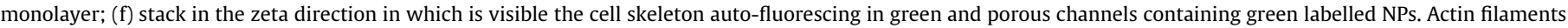
were stained by Phalloidin-Texas Red $(591 / 608 \mathrm{~nm})$ and nuclei by Hoechst 33342 (350/461 nm). Fe $\mathrm{O}_{4}$ NPs were labelled by BODIPY FL-EDA ( $500 / 510$ nm).

mode with three different excitation wavelengths for nuclei, actin and NPs. Image rendering was done using ImageJ software.

A control experiment was performed with digested NPs, CF, Fluoresceinmamine (FA, Sigma) and SFM in a transwell dish without cell monolayer and their translocation across the membrane was monitored using the same method followed when cells were present. Fluorescence at $520 \mathrm{~nm}$ was measured for media from the apical and basolateral chambers.

\section{Results and discussion}

\subsection{Stability of NPs in simulated gastrointestinal fluids}

NPs have been largely characterized in plasma for their possible applications in clinics as diagnostic and drug delivery systems (Jansch et al., 2012; Mahmoudi et al., 2011; Sakulkhu et al., 2014; Simberg et al., 2009). The intravenous administration of drugs is very common, but ingestion is the main route for oral nanoformulations and for NPs used as additives in food and food packaging. Thus, characterization of NPs in the GI environment is of primary interest.

As for NPs in blood, NPs in the GI tract will certainly interact with biomolecules present in this complex and dynamic environment forming a PC. However, not many studies reporting on the characterization of the PC associated with NPs subjected to digestion are reported in the literature. This is mainly due to the experimental difficulty in isolating PC NPs from such a dynamic environment without modifying their properties. For example, Jahn et al. (2011) studied the uptake of hemin-coupled iron hydroxide NPs on Caco-2 cells and they speculated a strong effect due to the colloidal stability of such NPs in the medium, but they did not perform any stability study. Pereira et al. (2013) found that Fe(III)-oxo hydroxide NPs forms ferrihydrite-like complexes after a simulated in vitro digestion. PC NPs could not be isolated from GI fluids without 


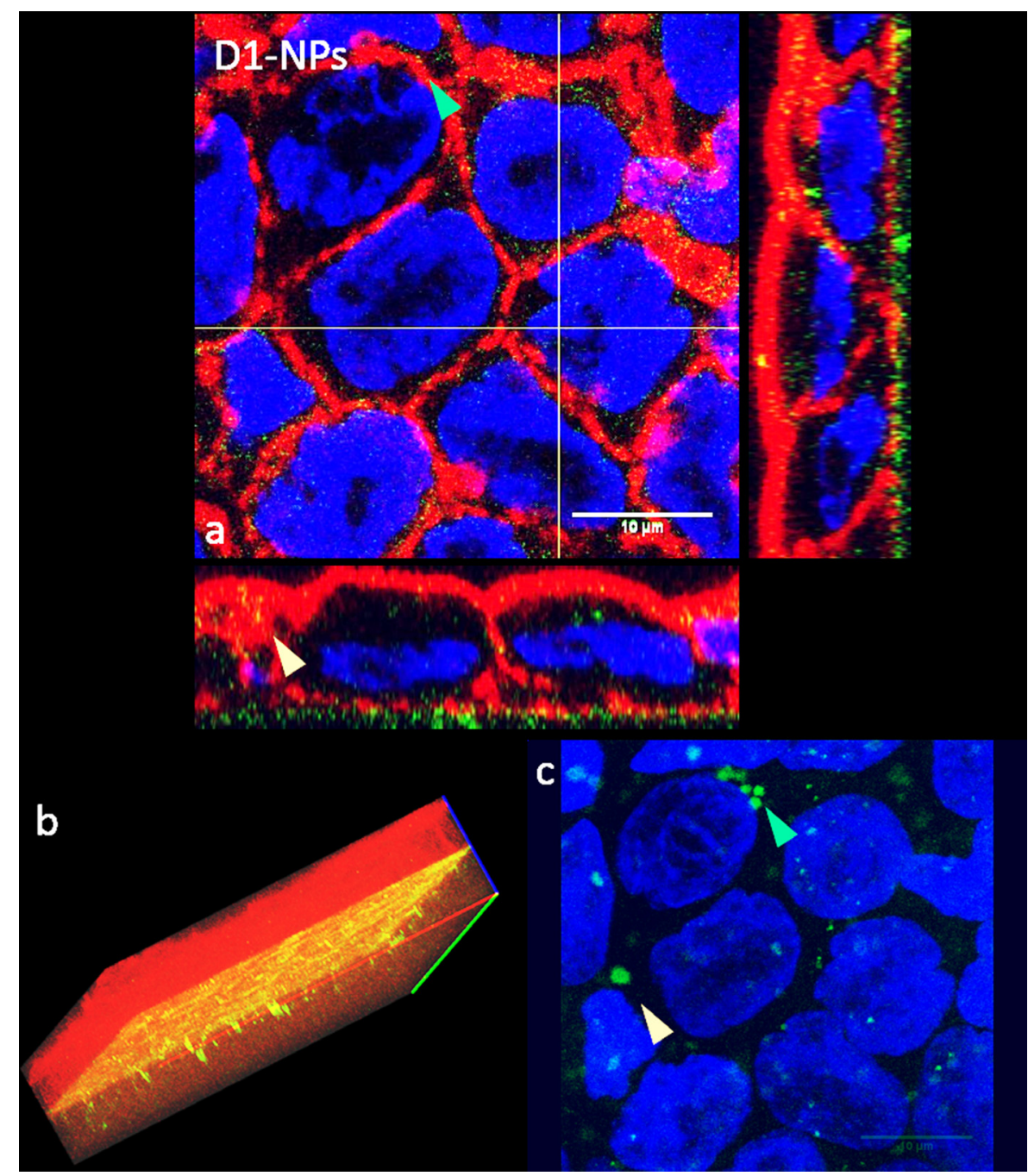

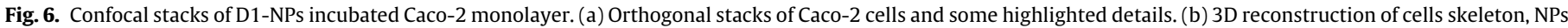

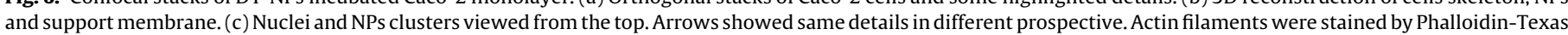
Red $(591 / 608 \mathrm{~nm})$ and nuclei by Hoechst 33342 (350/461 nm). $\mathrm{Fe}_{3} \mathrm{O}_{4}$ NPs were labelled by BODIPY FL-EDA (500/510 nm). Images were rendered using ImageJ.

aggregation, but they used the approach to synthesize ferrihydrite complexes ex novo for studying their biological response on Caco-2 cells, bypassing the isolation of such NPs from digestive fluids. Finally Yang et al. (2014) studied the behaviour of iron oxide NPs in GI fluids observing their tendency to aggregate if specific surface coating (citrate ions) were not performed.

In this study, we used fluorescently labelled carboxylated magnetite NPs. They were composed of a magnetite core, $\mathrm{Fe}_{3} \mathrm{O}_{4}$ of 10 $\mathrm{nm}$ and an amphiphilic polymer coating (poly (maleic)-alt-1octadecene) that makes them water-soluble and easily surface modifiable thanks to the carboxylic groups available to form amide bonds with primary amines (see Fig. SI1 in the SI) (Sun et al., 2003). In physiological buffer at pH 7.4 they exhibited a hydrodynamic diameter of about $50 \mathrm{~nm}$, a quite narrow size distribution (PdI of $0.20)$ and a negative $\mathrm{Zp}(-21 \mathrm{mV})$. We tested their stability over 4 $\mathrm{h}$ at $37{ }^{\circ} \mathrm{C}$ in simulated digestive fluids to assess the effect of $\mathrm{pH}$ and ionic strength before the addition of enzymes and food, thus before being coated by a PC. In Fig. 1 size distribution trends are reported for these $\mathrm{Fe}_{3} \mathrm{O}_{4}$ NPs in PBS, simulated salivary fluid (SSF) and simulated gastric fluid (SGF). NPs in simulated intestinal fluid (SIF) immediately precipitated likely due to the high electrolytes concentration that shields NPs surface negative charge (Bergin and Witzmann, 2013; Frenkel et al., 2005; Peters et al., 2012; Yang et al., 2014; Zimmermann and Müller, 2001). In SSF, the averaged hydrodynamic sizes of the NPs mostly increased with respect to those in PBS during the first hour of incubation, reaching a plateau with an average size almost double that of the starting one in PBS. PdI values were in contrast comparable to those in PBS. In SGF NP hydrodynamic sizes appeared to slowly increase over time to reach an average value almost three time larger than the starting one. On the other hand, PdI values appeared invariant with time. Overall, these results showed that when the NPs reach the gastric environment they form agglomerates of uniform dimensions.

\subsection{Simulated gastric and duodenal digestion of bread in the presence of NPS}

The isolation of PC-NPs complexes originating from NPs codigested with bread is very interesting but extremely challenging. In fact, bread is a common food in the daily diet but as all cereal based food it is a very complex matrix (Hoebler et al., 2002).

During the simulated digestion of bread, insoluble protein aggregates were formed particularly in the gastric phase. Hydrolysis occurred over time, proteins were converted into low molecular weight peptides, and food particulates decreased in size. Recently, Lichtenstein et al. (2015) performed simultaneous digestion of NPs, bread and other food. They studied the size and aggregation of in situ complexes by SAXS at the end of the duodenal phase, but 


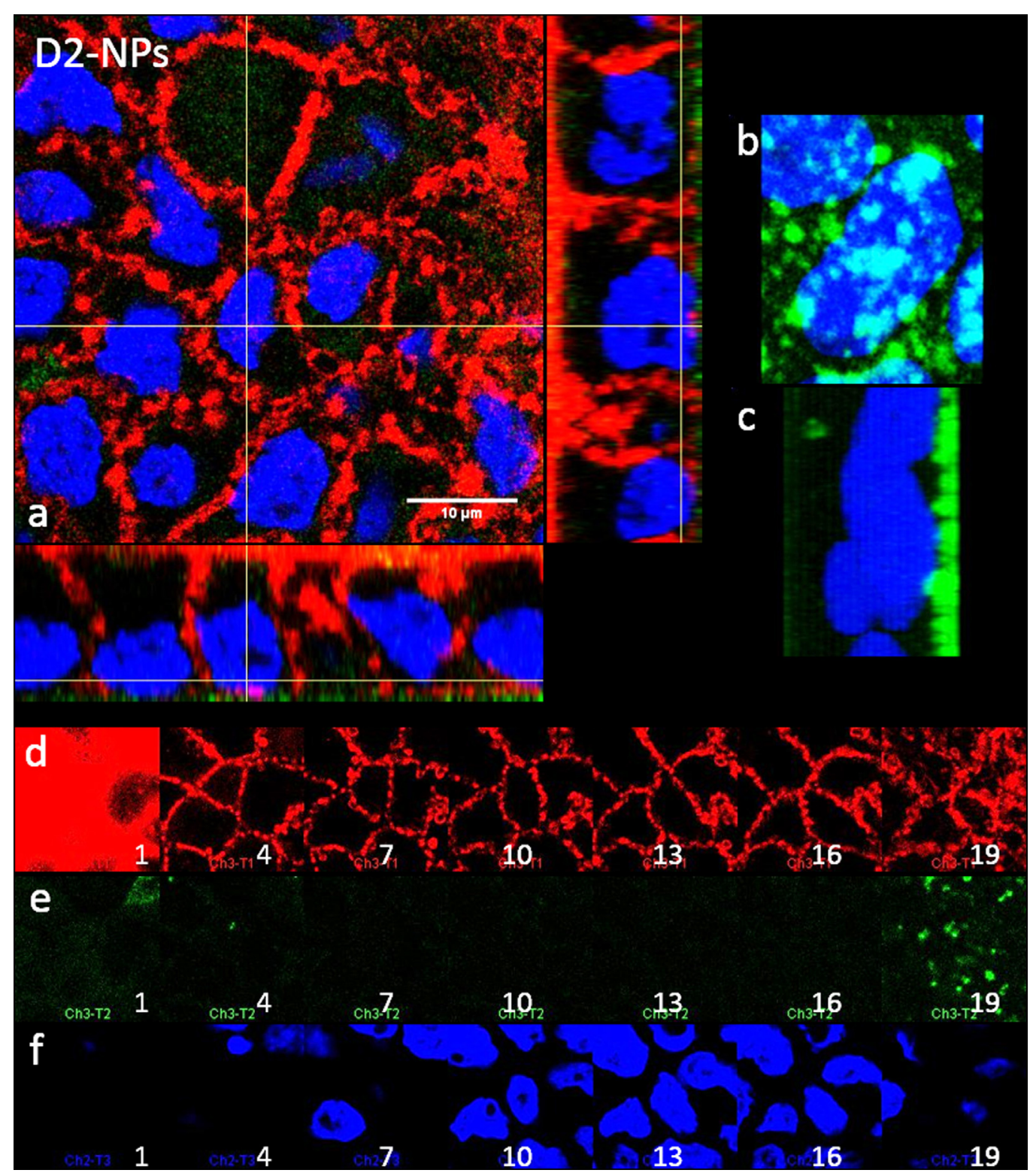

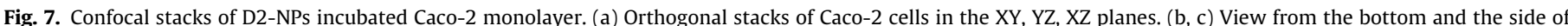

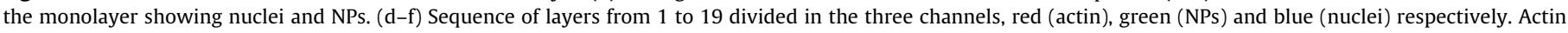

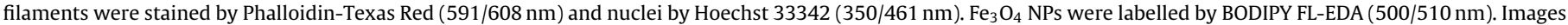
were rendered using ImageJ. (For interpretation of the references to color in figure legend, the reader is referred to the web version of the article.)

HC NPs were not isolated and characterized in terms of composition and evolution over time. In this work, we have focused on the evolution of the NPs during the different phases of the digestion with particular attention to the characterization of the structure and composition of protein corona NPs. In fact we exploited the methodology described in our previous work based on sucrose gradient ultracentrifugation (UC) for successfully recovering PC-NP complexes from both gastric and duodenal phases.

The recovery of PC-NP complexes from the gastric phase required the optimization of UC parameters (sucrose concentration, speed and time). We used a wide concentration gradient with a short and slow centrifugation (6.6-66\% at $48 \mathrm{k} \mathrm{rcf})$ to avoid colocalization of PC complexes and starch particulate. We achieved separation of NPs and unbound peptides. The NPs were located at the top of the gradient corresponding to a sucrose concentration between $10 \%$ and 20 w/w\% (upper zone in Fig. 2a), while starch residues were spread on the gradient at higher densities (lower zone in Fig. 2a). The application of standard centrifugation protocols, even trying different experimental conditions, did not allow the separation of PC NPs from starch residues, but lead to the formation of strong irreversible aggregates. PC NPs recovered by UC were characterized by DLS and showed a hydrodynamic size about three/four time larger compared to the size of the equivalent NPs in PBS, as reported in Table 2. During digestion, NPs density decreased as it can be inferred from NPs location in the sucrose gradient. Indeed, while pristine NPs moved to about $40 \mathrm{w} / \mathrm{w} \%$ sucrose concentration, the PC NPs only reached the area between $10 \%$ and $20 \%$. This is likely due to the formation of multi-particle protein agglomerates stabilized by the PC, which are characterized by a lower overall density depending on the partial specific volume and the frictional coefficient variations of the complexes. PC composition of the isolated NPs was determined by SDS-PAGE. In Fig. $2 \mathrm{~b}$, the lane labelled as G-NPs corresponds to the UC fractions where NPs subjected to gastric digestion were found (fractions 2-5). This sample was clearly enriched with proteins when compared to the same fractions of the control without NPs $\left(3 \mathrm{G}^{*}, 5 \mathrm{G}^{*}\right)$. Some bands of 
the PC around 36-40 kDa (probably a mixture of polypeptides from albumins and globulins) were also found in the analogous lanes of the control sample $\left(1 \mathrm{G}^{*}-5 \mathrm{G}^{*}\right)$, thus they might be contaminants from the environment and not associated with the corona. While a characteristic protein pattern, not observable in the equivalent lanes of the control, is observed at $M_{\mathrm{W}}$ lower than $36 \mathrm{kDa}$. A similar protein pattern, but much more diffuse, appeared in the control sample in the higher density fractions where starch residues were clearly visible.

The texture of the mixture after $2 \mathrm{~h}$ of duodenal digestion became liquid without solid residues. The agglomerates formed by NPs and peptides in the gastric phase partially disaggregated in duodenal conditions. UC on aliquots isolated from such a mix-ture was performed for $1 \mathrm{~h}$ at 195k rcf. After the run, a brown band (D2NPs) was visible at high sucrose concentration (fractions 14-16 at about 55 w/w\% sucrose concentration) as shown in Fig. 3a. A screening of all the fractions by size disclosed another population of PC complexes (D1-NPs) located from fraction 4 to fraction 9. Bile and unbound low-density peptides were located in the top of the sucrose gradient. Overall, two different populations of PC NPs were formed and characterized by hydrodynamic diameters smaller than $150 \mathrm{~nm}$. D1-NPs were about 20\% smaller in hydrodynamic size com-pared to D2-NPs, but they had a sensibly different density. Both complexes were characterized by negative $\mathrm{Zp}$, possibly because of the absorption of bile salts on their surface (Table 3). In Fig. 3b pro-tein corona profiles by SDS-PAGE are shown. As expected many peptides were found in the first fraction and their concentration decreased increasing the sucrose density and no peptides were detected in high-density sucrose bands $\left(11 D^{*}-17 D^{*}\right)$. The PCs asso-ciated to the complexes extracted by the two different fractions were completely different. The D1 PC was mainly composed of pancreatic enzymes (lipase and amylase at $55 \mathrm{kDa}$, trypsin and chy-motrypsin at $24 \mathrm{kDa}$ ) as it can be expected based on the composition of the duodenal environment. D2 PC was instead enriched with peculiar proteins such as the band at $55 \mathrm{kDa}$ and some other bands at higher molecular weights. Moreover, the diffuse band observed in the gastric sample seemed to be protected from digestion, while in the control sample without NPs the same bands in the high-density fractions $\left(15^{*}-16^{*}-17^{*} \mathrm{D}\right)$ were not detected.

LC-MS analysis on selected bands from gel in Figs. 2b and $3 \mathrm{~b}$ highlighted that G-NPs corona was enriched in albumins and globulins such as Serpin, GSP-1 Grain Softness Protein (17 kDa), albumin-2 (26 kDa) and Avenin-like A1 (19 kDa). Those proteins were mostly found in high molecular weight bands suggesting the presence of peptides aggregates. The diffuse band at low molecular weight contained mainly peptides from beta-amylase, 0.19 dimeric alpha-amylase inhibitor and albumin-2 indicating that they were preserved during digestion. Such proteins were also identified in the D2-NPs corona as listed in Table 4 (full proteomic character-ization can be found in SI Tables SI1 and SI2). To the best of our knowledge, this is the first time that proteomic analysis of PC from food containing digestive juices has been described. Moreover, the reported incomplete digestion of some proteins can have important biological implications considering that some of those peptides were recognized to be allergens (Akagawa et al., 2007) and could induce prolonged adverse reactions in the gut.

\subsection{Translocation and uptake of PC complexes}

There are many articles about uptake and translocation of NPs through monolayers of Caco-2 cells (Jahn et al., 2011; Zariwala et al., 2013) or co-culture that produce mucus (Kenzaoui et al., 2012). Brun et al. (2014) described titanium oxide NPs uptake in Caco-2 mono and co-cultures and in mice, studying the PC composition of NPs incubated in 10\% serum proteins and subjected to simulated digestion. However, none of these studies reported detailed descriptions of isolated PC NPs from digestive juices. Also Walczak et al. (2015a,b) highlighted the role of the PC, formed upon exposure to complete cell medium, on Caco-2 uptake. Lichtenstein et al. (2015), on the other hand, pointed out the importance of a food matrix during NPs in vitro digestion showing that the formation of the PC imparted colloidal stability to the NPs in the GI fluids.

Here, we focused on the characterization of PC-NP complexes formed during food-NP digestion, which were successfully isolated from the biological environment by a UC protocol developed in our lab. PC-NP complexes separated from the digestive chyme were applied to Caco-2 monolayers in a serum free environment. Fluorescence measurements did not detect NPs translocation to the basolateral chamber for any of the samples, so for ruling out the possibility that NPs transmembrane diffusion was hindered by the pore size (Hallez, 2012; Roth et al., 1996), a translocation experiment was performed without a cell monolayer, which demonstrated the ability of the NPs to translocate (see Fig. SI2 in SI). Nevertheless, NPs could agglomerate inside the cells and be transcytosed as larger aggregates that would not pass through membrane pores (Ye et al., 2013, 2015). Thus, confocal microscopy was used to elucidate NPs cellular localization as well as their passage through the pores of the insert membrane (Bannunah et al., 2014; Verano-Braga et al., 2014).

In Fig. 4, an overview of Caco-2 monolayers is displayed. Control samples incubated with PBS and carboxyfluorescein (CF) were characterized by normal cell architecture with intact actin skeleton and tight junctions. Slight alterations of the actin network were observed in the sample treated with pristine $\mathrm{NPs}\left(\mathrm{Fe}_{3} \mathrm{O}_{4}\right)$, while alterations in membrane morphology are evident for all the samples treated with PC NPs. The treatment of cells with PC NPs increased the number of vesicles in the apical membrane, as it can be seen in G-NPs and D1-NPs treated cells (Figs. 5a, b and 6a, b), while such vesicles were observed associated with the basal membrane in the cells incubated with D2-NPs highlighting transcytosis. For this sample, the orthogonal view shown in Fig. 7a displays the status of the cell walls very close to the insert membrane and in Fig. 7d clusters that co-localize with those vesicles associated with the basal membrane are shown (Fig. 7d, layer 19d-f). Those kinds of alterations could not be picked up by TEER as the values did not change significantly (Lichtenstein et al., 2015) (see Fig. SI3 in SI). Brun et al. (2014) showed that also titanium oxide NPs did not affect TEER values for monolayers indicating membrane integrity and unaffected paracellular transport of cells, but they also showed for the same samples metabolic abnormalities, oxidative stress and DNA damage (Bergin and Witzmann, 2013; Böhmert et al., 2013; Stern et al., 2012). PC composition might have a role in the morpho-logical alterations encountered: some peptides found in the corona of G-NPs such as serpin, alpha-amylase inhibitor, and lectin were digestion-protected and were found in the PC of D2NPs. Those proteins were shown to be allergens (Akagawa et al., 2007) and the presence of gliadin-derived peptides cannot be excluded. Gliadins are the gluten water-soluble component and the derived peptides were proved to induce cytotoxicity and apoptosis in Caco-2 cells with particular effect on membrane proteins and redox activities (Giovannini et al., 2000; Rivabene et al., 1999). However, more studies are necessary to investigate these speculations and prove the real involvement of the PC in these effects.

Confocal microscopy confirmed uptake of digested NPs and it was generally higher for PC NPs than for pristine $\mathrm{Fe}_{3} \mathrm{O}_{4} \mathrm{NPs}$. In particular, PC NPs seemed to induce the formation of invaginations in the intersections among cells (see Fig. SI4 in the SI). This effect of NP uptake enhancement induced by the PC is in agreement with other data in literature. Indeed cationic USPIONs (Kenzaoui et al., 2012), polystyrene NPs (Tenzer et al., 2013), polymeric NPs (Leroux et al., 1994), silver NPs (Lichtenstein et al., 2015) and pegylated core-shell NPs (Pelaz et al., 2015) were reported to show higher 
cellular uptake when bearing a PC but, in all these studies, the PC originated from plasma or serum.

Among digested samples, it is difficult to determine those that showed the highest NP uptake. For example, NPs from gastric diges-tion were quite monodispersed (see Table 2 ) and big clusters inside the cytoplasm were not detected, while NPs accumulated between the basal membrane of the cells and the polyester membrane sup-port. In Fig. 5c, a high density of NP clusters is observed with a view from the bottom of the basal membrane and in Fig. $5 d$ the passage of NPs through the porous channels is confirmed by a 3D rendering of a stack in the orthogonal direction from the top of the cells going through the support membrane.

After duodenal digestion, D1-NPs appeared in the cells mainly as big clusters enclosed in vesicles as shown in Fig. 6a and c with an orthogonal stack and a top view of the monolayer, respectively. Clusters seemed to be similar in size although the optical resolution does not allow an accurate determination. Moreover, the quantum yield of the fluorescent molecules might be affected by the envi-ronmental $\mathrm{pH}$, although it has been reported that the dye used is very little affected by solvent polarity and $\mathrm{pH}$ (Karolin et al., 1994). However, most of the NPs are located between the basal and the support membranes and at the top of the porous channels (Fig. 6b). It is likely, in this case, that channels were blocked by the clusters being larger than the nominal pore size, and indeed fluorescent spots were mainly located in the upper part of the support rather than in the lower part.

D2-NPs were both attached to the apical membrane (layer 1 of Fig. 7d-f) and spread throughout the cytoplasm surrounding nuclei (Fig. 7a and e, layers 7-10-13). The NPs inside the cells appeared as clusters. Large clusters were also located between adjacent cells (layer 4 in Fig. $7 d-f$ ) and on the bottom of the cells entrapped in vesicles (Fig. 7b and c). For all digested samples, accumulation between the basal membrane and the support seemed to take place. While paracellular transport can be excluded given the size of the NPs, transcytosis was confirmed especially in D2-NPs incubated cells displaying vesicles in close proximity to the basal membrane. Multiple endocytic energy-dependent routes (e.g. clathrin, calveolin mediated endocytosis) can be speculated, given the differences in size, density and corona composition of the PC complexes (Bannunah et al., 2014; Jahn et al., 2011). More images for digested NPs interacting with the cell are provided in the SI, Figs. S5-7.

\section{Conclusions}

In this paper, we have described for the first time PC NPs originating from the simultaneous digestion of NPs with food matrix. The PC NPs formed during the different phases of the digestive process were different in size and corona composition. Moreover, we observed that some corona proteins were shown to resist the duodenal digestion extending their persistance in the gut. This finding could be of interest in the study of peptides that cause immunological response like in celiac disease. Although we did not precisely quantify NP uptake in Caco-2 cells, we confirmed that the corona enhanced the uptake of magnetite NPs in agreement with previous results reported in the literature for other NPs bearing plasma or serum derived coronas. Furthermore, we managed to demonstrate that different coronas induced different alterations in the cell morphology. In addition, UC-based isolation of PC-NP complexes was highly successful in removing the excess GI fluids that have been shown to induce a certain level of cytotoxicity in previous results (Lichtenstein et al., 2015). Moreover, it is likely that differences in size, density and corona composition for the various PC-NP complexes may lead to different routes of uptake and translocation but this needs to be further investigated.

\section{Conflict of interest}

The authors declare no conflict of interest.

\section{Acknowledgements}

This work was supported by funds from University of East Anglia (UEA, UK) and the BBSRC through the ISP grant BB/J004545/1 to IFR. FBB thanks the financial support from Regione Lombardia (Fondo per lo Sviluppo e la Coesione-FAS 2007-2013). The authors thank Dr Francis Mulholland for LC-MS analysis.

\section{Appendix A. Supplementary data}

Supplementary data associated with this article can be found, in the online version, at http://dx.doi.org/10.1016/j.biocel.2015.10. 019.

\section{References}

Akagawa, M., Handoyo, T., Ishii, T., Kumazawa, S., Morita, N., Suyama, K., 2007. Proteomic analysis of wheat flour allergens. J. Agric. Food Chem. 55, 6863-6870.

Bannunah, A.M., Vllasaliu, D., Lord, J., Stolnik, S., 2014. Mechanisms of nanoparticle internalization and transport across an intestinal epithelial cell model: effect of size and surface charge. Mol. Pharm. 11, 4363-4373.

Bergin, I.L., Witzmann, F.A., 2013. Nanoparticle toxicity by the gastrointestinal route: evidence and knowledge gaps. Int. J. Biomed. Nanosci. Nanotechnol., 3 , http://dx.doi.org/10.1504/IJBNN.2013.054515.

Böhmert, L., Girod, M., Hansen, U., Maul, R., Knappe, P., Niemann, B., Weidner, S.M. Thünemann, A.F., Lampen, A., 2013. Analytically monitored digestion of silver nanoparticles and their toxicity on human intestinal cells. Nanotoxicology 8 , 631-642.

Borel, T. Sabliov, C.M., 2014. Nanodelivery of bioactive components for food applications: types of delivery systems, properties, and their effect on ADME profiles and toxicity of nanoparticles. Annu. Rev. Food Sci. Technol. 5, 197-213.

Brun, E., Barreau, F., Veronesi, G., Fayard, B., Sorieul, S., Chaneac, C., Carapito, C., Rabilloud, T., Mabondzo, A., Herlin-Boime, N., Carriere, M., 2014. Titanium dioxide nanoparticle impact and translocation through ex vivo, in vivo and in vitro gut epithelia. Part. Fibre Toxicol. 11, 13.

Cai, X., Ramalingam, R., Wong, H.S., Cheng, J., Ajuh, P., Cheng, S.H., Lam, Y.W., 2013. Characterization of carbon nanotube protein corona by using quantitative proteomics. Nanomedicine 9, 583-593.

Cedervall, T., Lynch, I., Lindman, S., Berggård, T., Thulin, E., Nilsson, H., Dawson, K.A., Linse, S., 2007. Understanding the nanoparticle-protein corona using methods to quantify exchange rates and affinities of proteins for nanoparticles. Proc. Natl. Acad. Sci. USA 104, 2050-2055.

Clift, M.J.D., Bhattacharjee, S., Brown, D.M., Stone, V., 2010. The effects of serum on the toxicity of manufactured nanoparticles. Toxicol. Lett. 198, 358-365.

Di Silvio, D., Rigby, N., Bajka, B., Mayes, A., Mackie, A., Baldelli Bombelli, F., 2015. Technical tip: high-resolution isolation of nanoparticle-protein corona complexes from physiological fluids. Nanoscale, 7.

Docter, D., Westmeier, D., Markiewicz, M., Stolte, S., Knauer, S.K., Stauber, R.H., 2015. The nanoparticle biomolecule corona: lessons learned - challenge accepted? Chem. Soc. Rev. 44, 6094-6121.

Ensign, L.M., Cone, R., Hanes, J., 2012. Oral drug delivery with polymeric nanoparticles: the gastrointestinal mucus barriers. Adv. Drug Deliv. Rev. 64, 557-570.

Foroozandeh, P., Aziz, A.A., 2015. Merging worlds of nanomaterials and biological environment: factors governing protein corona formation on nanoparticles and its biological consequences. Nanoscale Res. Lett. 10, 221.

Frenkel, Y.V., Clark, A.D., Das, K., Wang, Y.-H., Lewi, P.J., Janssen, P.A.J., Arnold, E., 2005. Concentration and $\mathrm{pH}$ dependent aggregation of hydrophobic drug molecules and relevance to oral bioavailability. J. Med. Chem. 48, 1974-1983.

Ghavami, M., Saffar, S., Abd Emamy, B., Peirovi, A., Shokrgozar, M.A., Serpooshan, V., Mahmoudi, M., 2013. Plasma concentration gradient influences the protein corona decoration on nanoparticles. RSC Adv. 3, 1119-1126.

Giovannini, C., Sanchez, M., Straface, E., Scazzocchio, B., Silano, M., De Vincenzi, M. 2000. Induction of apoptosis in Caco-2 cells by wheat gliadin peptides. Toxicology 145, 63-71.

Hadjidemetriou, M., Al-Ahmady, Z., Mazza, M., Collins, R.F., Dawson, K., Kostarelos, K., 2015. In vivo biomolecule corona around blood-circulating clinically used and antibody-targeted lipid bilayer nanoscale vesicles. ACS Nano 9, 8142-8156.

Hallez, Y., 2012. Analytical and numerical computations of the van der Waals force in complex geometries: application to the filtration of colloidal particles. Colloids Surf. A: Physicochem. Eng. Asp. 414, 466-476.

Hoebler, C., Lecannu, G., Belleville, C., Devaux, M.-F., Popineau, Y., Barry, J.-L., 2002. Development of an in vitro system simulating bucco-gastric digestion to assess the physical and chemical changes of food. Int. J. Food Sci. Nutr. 53, 389-402. 
Hummel, B.C., 1959. A modified spectrophotometric determination of chymotrypsin, trypsin, and thrombin. Can. J. Biochem. Physiol. 37, 1393-1399. Jahn, M.R., Shukoor, I., Tremel, W., Wolfrum, U., Kolb, U., Nawroth, T., Langguth, P., 2011. Hemin-coupled iron(III)-hydroxide nanoparticles show increased uptake in Caco-2 cells. J. Pharm. Pharmacol. 63, 1522-1530.

Jansch, M., Stumpf, P., Graf, C., Rühl, E., Müller, R.H., 2012. Adsorption kinetics of plasma proteins on ultrasmall superparamagnetic iron oxide (USPIO) nanoparticles. Int. J. Pharm. 428, 125-133.

Karolin, J., Johansson, L.B.A., Strandberg, L., Ny, T., 1994. Fluorescence and absorption spectroscopic properties of dipyrrometheneboron difluoride (BODIPY) derivatives in liquids lipid membranes, and proteins. J. Am. Chem. Soc. 116, 7801-7806.

Kenzaoui, B.H., Vilà, M.R., Miquel, J.M., Cengelli, F., Juillerat-Jeanneret, L., 2012. Evaluation of uptake and transport of cationic and anionic ultrasmall iron oxide nanoparticles by human colon cells. Int. J. Nanomed. 7, 1275-1286. Kreyling, W.G., Fertsch-Gapp, S., Schäffler, M., Johnston, B.D., Haberl, N., Pfeiffer, C., Diendorf, J., Schleh, C., Hirn, S., Semmler-Behnke, M., Epple, M., Parak, W.J., 2014. In vitro and in vivo interactions of selected nanoparticles with rodent serum proteins and their consequences in biokinetics. Beilstein J. Nanotechnol. $5,1699-1711$.

Lefebvre, D.E., Venema, K., Gombau, L., Valerio, L.G., Raju, J., Bondy, G.S., Bouwmeester, H., Singh, R.P., Clippinger, A.J., Collnot, E.-M., Mehta, R., Stone, V., 2014. Utility of models of the gastrointestinal tract for assessment of the digestion and absorption of engineered nanomaterials released from food matrices. Nanotoxicology, 1-20.

Leroux, J.-C., Gravel, P., Balant, L., Volet, B., Anner, B.M., Allémann, E., Doelker, E., Gurny, R., 1994. Internalization of poly(D,L-lactic acid) nanoparticles by isolated human leukocytes and analysis of plasma proteins adsorbed onto the particles. J. Biomed. Mater. Res. 28, 471-481.

Lichtenstein, D., Ebmeyer, J., Knappe, P., Juling, S., Böhmert, L., Selve, S., Niemann, B., Braeuning, A., Thünemann Andreas, F., Lampen, A., 2015. Impact of food components during in vitro digestion of silver nanoparticles on cellular uptake and cytotoxicity in intestinal cells. Biol. Chem. 396, 1255-1264.

Lin, C.-A.J., Sperling, R.A., Li, J.K., Yang, T.-Y., Li, P.-Y., Zanella, M., Chang, W.H., Parak, W.J., 2008. Design of an amphiphilic polymer for nanoparticle coating and functionalization. Small 4, 334-341.

Lundqvist, M., Stigler, J., Elia, G., Lynch, I., Cedervall, T., Dawson, K.A., 2008. Nanoparticle size and surface properties determine the protein corona with possible implications for biological impacts. Proc. Natl. Acad. Sci. U.S.A. 105, $14265-14270$

Lynch, I., Cedervall, T., Lundqvist, M., Cabaleiro-Lago, C., Linse, S., Dawson, K.A., 2007. The nanoparticle-protein complex as a biological entity; a complex fluids and surface science challenge for the 21 st century. Adv. Colloid Interface Sci. 134-135, 167-174.

Mahmoudi, M., Shokrgozar, M.A., Sardari, S., Moghadam, M.K., Vali, H., Laurent, S. Stroeve, P., 2011. Irreversible changes in protein conformation due to interaction with superparamagnetic iron oxide nanoparticles. Nanoscale 3 , 1127-1138.

Maiorano, G., Sabella, S., Sorce, B., Brunetti, V., Malvindi, M.A., Cingolani, R., Pompa, P.P., 2010. Effects of cell culture media on the dynamic formation of proteinnanoparticle complexes and influence on the cellular response. ACS Nano 4, 7481-7491.

Minekus, M. Alminger, M., Alvito, P., Ballance, S., Bohn, T., Bourlieu, C. Carriere, F, et al., 2014. A standardised static in vitro digestion method suitable for food an international consensus. Food Funct. 5, 1113-1124.

Monopoli, M.P., Aberg, C., Salvati, A., Dawson, K.A., 2012. Biomolecular coronas provide the biological identity of nanosized materials. Nat. Nano 7, 779-786.

Pelaz, B., del Pino, P., Maffre, P., Hartmann, R., Gallego, M., Rivera-Fernández, S., de la Fuente, J.M., Nienhaus, G.U., Parak, W.J., 2015. Surface functionalization of nanoparticles with polyethylene glycol: effects on protein adsorption and cellular uptake. ACS Nano 9, 6996-7008.

Peng, Q., Zhang, S., Yang, Q., Zhang, T., Wei, X.-Q., Jiang, L., Zhang, C.-L., Chen, Q.-M., Zhang, Z.-R., Lin, Y.-F., 2013. Preformed albumin corona, a protective coating for nanoparticles based drug delivery system. Biomaterials 34, 8521-8530.

Pereira, D.I.A., Mergler, B.I., Faria, N., Bruggraber, S.F.A., Aslam, M.F., Poots, L.K., Prassmayer, L., Lönnerdal, B., Brown, A.P., Powell, J.J., 2013. Caco-2 cell acquisition of dietary iron(III) invokes a nanoparticulate endocytic pathway. PLOS ONE 8, e81250.

Peters, R., Kramer, E., Oomen, A.G., Herrera Rivera, Z.E., Oegema, G., Tromp, P.C., Fokkink, R., Rietveld, A., Marvin, H.J.P., Weigel, S., Peijnenburg, A.A.C.M., Bouwmeester, H., 2012. Presence of nano-sized silica during in vitro digestion of foods containing silica as a food additive. ACS Nano 6, 2441-2451.
Rivabene, R., Mancini, E., De Vincenzi, M., 1999. In vitro cytotoxic effect of wheat gliadin-derived peptides on the Caco-2 intestinal cell line is associated with intracellular oxidative imbalance: implications for coeliac disease. Biochim. Biophys. Acta 1453, 152-160.

Roth, C.M., Neal, B.L., Lenhoff, A.M., 1996. Van der Waals interactions involving proteins. Biophys. J. 70, 977-987.

Sakulkhu, U., Mahmoudi, M., Maurizi, L., Salaklang, J., Hofmann, H., 2014. Protein corona composition of superparamagnetic iron oxide nanoparticles with various physico-chemical properties and coatings. Sci. Rep. 4, 5020.

Setyawati, M.I., Tay, C.Y., Leong, D.T., 2015. Mechanistic investigation of the biological effects of $\mathrm{SiO}_{2}, \mathrm{TiO}_{2}$, and $\mathrm{ZnO}$ nanoparticles on intestinal cells. Small $11,3458-3468$

Sherwood, V., Di Silvio, D., Baldelli Bombelli, F., 2014. Nanoscopic agents in a physiological environment: the importance of understanding their characteristics. Top. Med. Chem., 1-26.

Simberg, D., Park, J.-H., Karmali, P.P., Zhang, W.-M., Merkulov, S., McCrae, K., Bhatia, S.N., Sailor, M., Ruoslahti, E., 2009. Differential proteomics analysis of the surface heterogeneity of dextran iron oxide nanoparticles and the implications for their in vivo clearance. Biomaterials 30, 3926-3933.

Soenen, S.J., Parak, W.J., Rejman, J., Manshian, B., 2015. (Intra)cellular stability of inorganic nanoparticles: effects on cytotoxicity particle functionality, and biomedical applications. Chem. Rev. 115, 2109-2135.

Stern, S.T., Adiseshaiah, P.P., Crist, R.M., 2012. Autophagy and lysosomal dysfunction as emerging mechanisms of nanomaterial toxicity. Part. Fibre Toxicol. 9, 20 .

Sun, S., Zeng, H., Robinson, D.B., Raoux, S., Rice, P.M., Wang, S.X., Li, G., 2003. Monodisperse $\mathrm{MFe}_{2} \mathrm{O}_{4}(\mathrm{M}=\mathrm{Fe}, \mathrm{Co} \mathrm{Mn})$ nanoparticles. J. Am. Chem. Soc. 126,

273-279.

Tenzer, S., Docter, D., Kuharev, J., Musyanovych, A., Fetz, V., Hecht, R., Schlenk, F., Fischer, D., Kiouptsi, K., Reinhardt, C., Landfester, K., Schild, H., Maskos, M., Knauer, S.K., Stauber, R.H., 2013. Rapid formation of plasma protein corona critically affects nanoparticle pathophysiology. Nat. Nano 8, 772-781.

Treuel, L., Docter, D., Maskos, M., Stauber, R.H., 2015. Protein corona - from molecular adsorption to physiological complexity. Beilstein J. Nanotechnol. 6,

857-873.

Verano-Braga, T., Miethling-Graff, R., Wojdyla, K., Rogowska-Wrzesinska, A. Brewer, J.R., Erdmann, H., Kjeldsen, F., 2014. Insights into the cellular response triggered by silver nanoparticles using quantitative proteomics. ACS Nano 8 , 2161-2175.

Walczak, A.P., Kramer, E., Hendriksen, P.J.M., Helsdingen, R., van der Zande, M., Rietjens, I.M.C.M., Bouwmeester, H., 2015a. In vitro gastrointestinal digestion increases the translocation of polystyrene nanoparticles in an in vitro intestinal co-culture model. Nanotoxicology, 1-9.

Walczak, A.P., Kramer, E., Hendriksen, P.J.M., Tromp, P., Helsper, J.P.F.G., van der Zande, M., Rietjens, I.M.C.M., Bouwmeester, H., 2015b. Translocation of differently sized and charged polystyrene nanoparticles in in vitro intestinal cell models of increasing complexity. Nanotoxicology 9, 453-461.

Walczyk, D., Bombelli, F.B., Monopoli, M.P., Lynch, I., Dawson, K.A., 2010. What the cell "Sees" in bionanoscience. J. Am. Chem. Soc. 132, 5761-5768.

Walkey, C.D., Olsen, J.B., Song, F., Liu, R., Guo, H., Olsen, D.W.H., Cohen, Y., Emili, A., Chan, W.C.W., 2014. Protein corona fingerprinting predicts the cellular interaction of gold and silver nanoparticles. ACS Nano 8, 2439-2455. Woolnough,

J.W., Bird, A.R., Monro, J.A., Brennan, C.S., 2010. The effect of a brief salivary $\alpha$-amylase exposure during chewing on subsequent in vitro starch digestion curve profiles. Int. J. Mol. Sci. 11, 2780-2790.

Yang, S.-C., Paik, S.-Y.-R., Ryu, J., Choi, K.-O., Kang, T.S., Lee, J.K., Song, C.W., Ko, S. 2014. Dynamic light scattering-based method to determine primary particle size of iron oxide nanoparticles in simulated gastrointestinal fluid. Food Chem. $161,185-191$.

Ye, D., Dawson, K.A., Lynch, I., 2015. A TEM protocol for quality assurance of in vitro cellular barrier models and its application to the assessment of nanoparticle transport mechanisms across barriers. Analyst 140 , 83-97.

Ye, D., Raghnaill, M.N., Bramini, M., Mahon, E., Aberg, C., Salvati, A., Dawson, K.A 2013. Nanoparticle accumulation and transcytosis in brain endothelial cell layers. Nanoscale 5, 11153-11165.

Zariwala, M.G., Elsaid, N., Jackson, T.L., Corral López, F., Farnaud, S., Somavarapu, S. Renshaw, D., 2013. A novel approach to oral iron delivery using ferrous sulphate loaded solid lipid nanoparticles. Int. J. Pharm. 456, 400-407.

Zimmermann, E., Müller, R.H., 2001. Electrolyte- and pH-stabilities of aqueous solid lipid nanoparticle $\left(\mathrm{SLN}^{\mathrm{TM}}\right)$ dispersions in artificial gastrointestinal media. Eur. J. Pharm. Biopharm. 52, 203-210. 